\title{
Research on Performance Evaluation Index System and Empirisiam of Network Marketing
}

\author{
Yichao Wan \\ Department of E-commerce, Jiangxi University of Finance and Economics, Nanchang 330013, \\ China.
}

824380336@qq.com

\begin{abstract}
Keywords: Network marketing; Performance evaluation; Indicator system; Fuzzy comprehensive assessment; Balanced Scorecard.
\end{abstract}

\begin{abstract}
Conducting network marketing performance evaluation has great significance for enterprises to fully understand their own situation and make optimal marketing decisions, including indicator system construction and empirical research. This paper takes the performance evaluation of network marketing as the research object; Firstly, reconstructing four dimensions based on the in-depth analysis of the differences between the Balanced Scorecard and the network marketing performance evaluation; Secondly, this paper improves the Balanced Scorecard with the system dynamics and analyzes the causality among indicators to construct an evaluation indicator system with a clear hierarchy structure; Thirdly, using the analytic hierarchy process and fuzzy comprehensive assessment as the basic model, taking Dangdang.com as the sample data, an empirical research of network marketing performance is conducted. Finally, the validity and reliability of the indicator system are verified by the indicator validity evaluation method, the accuracy of the empirical evaluation result is $7.77 \%$, and the empirical results and accuracy can satisfy the practical requirements.
\end{abstract}

\section{Introduction}

For modern enterprise development, network marketing plays an important role in establishing brand image and promoting product sales. At present, Chinese enterprises have launched a variety of network marketing activities. Network marketing performance evaluation can help enterprises understand whether their marketing activities have achieved the expected goals and find out what deficiencies exist in marketing activities to better guide the current and future marketing activities. Therefore, it is of great significance to conduct research on network marketing performance evaluation including indicator system construction and empirical research.

\section{Literature Review}

This paper collates and analyzes the typical achievements of domestic and overseas researches on performance evaluation indicators of network marketing, as shown in Table 1.

Table 1. Domestic and overseas network marketing performance evaluation indicator literature

review

\begin{tabular}{ccc}
\hline Author & Time & Typical indicators and dimensions \\
\hline Rayport & 2001 & 5 dimensions of opportunity, user interface, business model, brand, finance [1] \\
Thompson & 2005 & 5 dimensions including technology, content, reliability, interactivity, navigation [2] \\
Ray & 2006 & Constructing indicator system from website's view [3] \\
Wang Zhanping & 2009 & 4 dimensions including finance, customer, internal process, learning and growth [4] \\
Christos & 2010 & 4 dimensions of customer, network security, security service, online privacy [5] \\
Elsalam & 2013 & 2 dimensions of user satisfaction and network marketing business strategies [6] \\
Yu Baolong & 2014 & 5 dimensions including finance, market, website, security, service [7] \\
Li Jue & 2017 & 5 dimensions including finance, market competition, advertising, network promotion, service [8] \\
\hline
\end{tabular}

Through the above analysis, we can see that the indicator system dimensions are still uncertain and the indicator hierarchy is not clear, which make it difficult for subsequent enterprises to understand 
and operate and empirical evaluation. Therefore, it is very important to construct a complete and reasonable indicator system.

\section{Establishment of Evaluation Indicator System}

\subsection{Evaluation Indicator System Dimension Design.}

BSC is a wildly used and accepted tool for performance evaluation and management. The differences between the four dimensions of BSC and the dimensions of network marketing performance evaluation are shown as follows. (1)Differences in the financial dimension. The main sources of financial revenue include the daily incomes, liabilities and shareholders' inputs. The income of enterprises that develop network marketing relies heavily on marketing effectiveness. (2) Differences in the customer dimension. Many enterprises adopt some indicator that represent the past. It does not really reveal the key driver factors for improving performance. While in order to develop network marketing, it is necessary to improve customer satisfaction and loyalty. (3)Differences in the internal process dimension. The internal process performance of enterprises comes from the core competitiveness. When developing network marketing, enterprises must meet consumer demands in all aspects, so the design of the website is very important. Enterprises must fully understand their own competitiveness. (4)Differences in the learning and growth dimension. Learning and growth level emphasizes that enterprises should innovate and maintain their competitiveness. In order to achieve better marketing results, employees need continuous improvement and technology should be innovative, so as to meet the diverse needs of consumers.

Based on the above analysis, reconstructing an indicator system covers four dimensions of input and output, consumer, website performance, innovation and growth.

\subsection{Establishment of Evaluation Indicator System Based on BSC.}

\subsubsection{Causal Analysis of Website Performance Dimension.}

There are some inherent defects in the research of the interaction between indicators of the BSC [6], this paper amends and improves the BSC with the help of the causal analysis of system dynamics to determine the concrete evaluation indicator. Considering length limitations, the causalities of some indicators are presented ("+" indicates the positive gain).

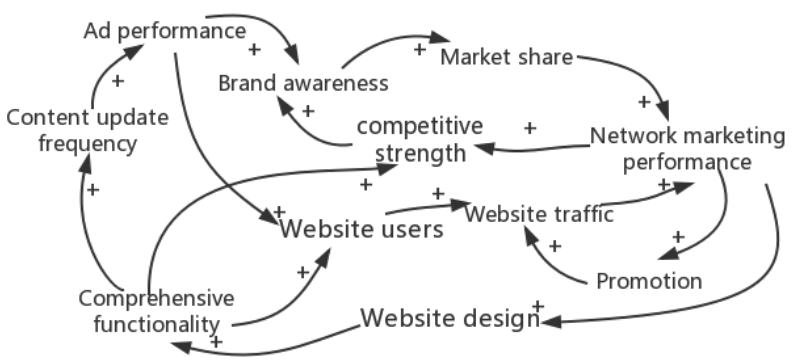

Fig. 1 Causal analysis of website performance dimension

\subsubsection{Establishment of evaluation indicator system.}

Combining with the causal analysis of indicators, and referencing to relevant literatures, expert interviews and questionnaires, this paper selects 3 second indicators and 7 third indicators to construct internal process dimension. In the same way, the indicators of input and output, consumer innovation and growth dimensions are constructed, and the ultimate performance evaluation system of network marketing is obtained (Table 2). The final evaluation indicator system contains 4 first indicators, 7 second indicators and 16 third indicators.

\section{Empirical Research on Network Marketing Performance Evaluation}

\subsection{Model Selection.}

BP neural network, DEA, gray correlation analysis method, SEM and other methods are used in performance evaluation to different extents. However, these methods are prone to error because of the 
high subjective randomness. Considering the fuzziness of many influencing factors in the evaluation indicator and the advantages of FCA in evaluating multi-indicator system,this paper proposes a fuzzy evaluation method based on AHP[3].

\subsection{Empirical Research.}

\subsubsection{Sample Selection and Data Acquisition.}

Whether the choice of the research sample is appropriate will have important influence on the conclusion. Therefore, this paper not only considers the specific circumstances of the enterprises and their representativeness and typicality in the industry, but also the feasibility and possibility of data acquisition in the process of specific selection. This paper selects Dangdang.com as the evaluation object and the concrete application and model verification of performance evaluation of network marketing.

Then, this paper determines the qualitative indicators in the evaluation indicator system through investigation, obtains data by internet convenience and online questionnaires. On the basis of data acquired, the quantitative indicators are evaluated by consulting experts and referring to existing standards.

\subsubsection{Determine the Factor Sets and Evaluation Sets of Network Marketing Performance Evaluation.}

According to the previous analysis, the evaluation indicator system is divided into three layers. The evaluation factor set of the first layer is $U=\left(u_{1}, u_{2}, u_{3}, u_{4}\right)$. The rest is listed in Table 2.According to the complex feature of the network marketing indicator system, this paper sets five evaluation levels, that is $V=\left\{v_{1}, v_{2}, v_{3}, v_{4}, v_{5}\right\}=\{$ very good, good, general, not good, bad $\}$.

\subsubsection{Determine the Weights of Evaluation Indicators.}

This paper chooses the AHP to determine the weights, and the final results are shown in Table 2.

Table 2. Performance evaluation indicator data of network marketing

\begin{tabular}{|c|c|c|c|c|c|}
\hline First indicators & Weights & Second indicators & Weights & Third indicators & Weights \\
\hline \multirow{3}{*}{$\begin{array}{l}\text { Input and } \\
\text { output } u_{1}\end{array}$} & \multirow{3}{*}{0.1221} & \multirow{3}{*}{$\begin{array}{l}\text { Operational } \\
\text { aspect } u_{11}\end{array}$} & \multirow{3}{*}{1} & Sales growth rate $u_{111}$ & 0.40 \\
\hline & & & & Profit growth rate $u_{112}$ & 0.40 \\
\hline & & & & Operation cost $u_{113}$ & 0.20 \\
\hline \multirow{2}{*}{ Customer $u_{2}$} & \multirow{2}{*}{0.4231} & Consumer & \multirow{2}{*}{1} & Consumer satisfaction $u_{211}$ & 0.50 \\
\hline & & relation $u_{21}$ & & Consumer loyalty $u_{212}$ & 0.50 \\
\hline \multirow{7}{*}{$\begin{array}{c}\text { Website } \\
\text { performance } \\
u_{3}\end{array}$} & \multirow{7}{*}{0.2274} & Competitive & \multirow{2}{*}{0.16} & Brand awareness $u_{311}$ & 0.67 \\
\hline & & power $u_{31}$ & & Market share $u_{312}$ & 0.33 \\
\hline & & Promotion aspect & \multirow{2}{*}{0.30} & Website traffic $u_{321}$ & 0.33 \\
\hline & & $u_{32}$ & & Ad performance $u_{322}$ & 0.67 \\
\hline & & \multirow{3}{*}{$\begin{array}{l}\text { Website design } \\
\qquad u_{33}\end{array}$} & \multirow{3}{*}{0.54} & Website security $u_{331}$ & 0.71 \\
\hline & & & & Operation convenience $u_{332}$ & 0.18 \\
\hline & & & & Comprehensive functionality $u_{333}$ & 0.11 \\
\hline \multirow{4}{*}{$\begin{array}{l}\text { Innovation and } \\
\text { growth } u_{4}\end{array}$} & \multirow{4}{*}{0.2274} & Technical aspect & \multirow{2}{*}{0.50} & Website innovation $u_{411}$ & 0.75 \\
\hline & & $u_{41}$ & & Information technology level $u_{412}$ & 0.25 \\
\hline & & Employee aspect & \multirow{2}{*}{0.50} & Staff training efficiency $u_{421}$ & 0.50 \\
\hline & & $u_{42}$ & & Staff innovation ability $u_{422}$ & 0.50 \\
\hline
\end{tabular}

\subsubsection{Evaluation Results.}

Based on the above data, the fuzzy statistical method is used to calculate the degree of membership of all indicators.

According to the formula 1 for first-level fuzzy comprehensive evaluation.

$$
B_{i j}=w_{i j} \bullet R_{i j}
$$


$R_{i j}$ represents the fuzzy evaluation matrix of each factor in the third-level indicator, $w_{i j}$ represents the corresponding weight distribution sets, Such as $B_{11}$ calculation result as follows.

$$
B_{11}=w_{11} \bullet R_{11}=\left[\begin{array}{lll}
0.4 & 0.4 & 0.2
\end{array}\right] \bullet\left[\begin{array}{ccccc}
0 & 0 & 1 & 0 & 0 \\
0 & 0 & 0 & 1 & 0 \\
0 & 1 & 0 & 0 & 0
\end{array}\right]=\left[\begin{array}{lllll}
0 & 0.2 & 0.4 & 0.4 & 0
\end{array}\right]
$$

The same methods can be used to calculate the secondary indicator weight sets and third-level fuzzy evaluation results as follows.

$$
B=\left[\begin{array}{lllll}
0.2135 & 0.4219 & 0.2728 & 0.0918 & 0
\end{array}\right]
$$

The weighted average method is used to calculate the comprehensive evaluation results of all indicators. Assignmenting the evaluation sets V:5,4,3,2,1, Taking $b_{i}$ as the weight, The result of the final evaluation is calculated by weighted average of the evaluation level sets $(5,4,3,2,1)$ and each level $b_{i}$.

Table 3. Evaluation results data table

\begin{tabular}{cc}
\hline Dimensions & Evaluation results \\
\hline Input and output & 2.800 \\
Customer & 3.945 \\
Website performance & 4.192 \\
Innovation and growth & 3.487 \\
Network marketing & 3.7571 \\
\hline
\end{tabular}

Through the comprehensive evaluation results, the comprehensive performance evaluation score of network marketing is 3.7571, The comprehensive performance of network marketing is not particularly good.

\section{Experiment Confirmation}

\subsection{Evaluation Indicator System RST Test.}

This paper uses the RST evaluation method to test the validity of the evaluation indicators. The RST shows the validity of the indicator system through the redundancy degree $(R D)$ and sensitivity degree $(S D)$. The calculation methods can be seen in referenc[1].

Table 4 . Validity test results of index system

\begin{tabular}{ccc}
\hline & $R D$ & $S D$ \\
\hline indicator evaluation system of network marketing & 0.233 & 1.786 \\
\hline
\end{tabular}

According to Table 4, the redundancy degree is less than 0.5 and the sensitivity degree is less than 5. The results show that the performance evaluation indicator system of network marketing is valid.

\subsection{Comparison Test of Evaluation Results.}

This paper selects 7 sample indicators randomly, then uses the BP neural network and the model of this paper to make an empirical evaluation. In view of the high evaluation accuracy of the BP neural network [8], the evaluation results of the BP neural network are used as the benchmark value and compared with the evaluation results of this paper. Among them, the step size (domain value and direction) in the actual operation is manually adjusted based on the preliminary evaluation result of this paper, so as to solve the inherent shortcoming of slow convergence speed when the BP neural network operates alone. From the table, it can be seen that the error values are all less than $10 \%$, so the evaluation results of this paper have validity and credibility.

Table 5. Error table of two model evaluation results

\begin{tabular}{c|c|c|}
\hline $\begin{array}{c}\text { This paper } \\
\text { evaluation results }\end{array}$ & BP neural network evaluation results & Error \\
\hline 3.640 & 4.000 & $9.00 \%$ \\
\hline 2.750 & 3.000 & $8.33 \%$ \\
\hline 4.021 & 4.300 & $6.49 \%$ \\
\hline 3.425 & 3.800 & $9.87 \%$ \\
\hline 4.354 & 4.600 & $5.35 \%$ \\
\hline 3.461 & 3.700 & $6.46 \%$ \\
\hline 3.187 & 3.500 & $8.94 \%$ \\
\hline
\end{tabular}




\section{Conclusion}

This paper analyzes the existing network marketing performance evaluation indicator system as well as the difference between the balanced scorecard and network marketing performance evaluation. Using the idea of system dynamics causality, the balanced scorecard is improved, and an evaluation index system with a definite dimension and a clear hierarchy structure is constructed. The indicator weights are determined through analytic hierarchy process, and an network marketing performance evaluation model is constructed based on fuzzy comprehensive evaluation. Taking Dangdang as an example, an empirical evaluation is conducted to provide a theoretical basis and practical method for further research on network marketing performance.

\section{Acknowledgements}

This work is supported by scientific research project of the education department of Jiangxi Province (GJJ150458).

\section{References}

[1]. Rayport, Jawoski. Equilibrium price dispersion.Econometrica.Vol.51(2001). No.6, P.955-969.

[2]. Thompson,S.H.Teo.Usage and effectiveness of online marketing tools among Business-to-Consumer(B2C)firms in Singapore. International Journal of Information Management.Vol.25(2004). No.3, P.203-213.

[3]. Ray W, Lesley W. Website performance measurement: promise and reality. Managing Service Quality.Vol.16(2006). No.6, P.654-670.

[4]. Wang Zhanping. Research on constructing the evaluation index system of enterprise E-marketing performance. Library and Information Service.Vol.54(2010).No.12,P.132-135.

[5]. Christos D, Dimitims N.S.Network security: status and prospects. Science Press,2010,p.12-17.

[6]. Elsalam,H.K.M.A.,Razek,M.A.,Eldin,M.M.True performance evaluation methodology in E-marketing.IEEE.Vol.11(2013).No.6,P.67-72.

[7]. Yu Baoling: Research on performance evaluation of network marketing of e-commerce enterprise (Business Management, Liaoning University, China 2014). p.1

[8]. Li Jue, Chen Juanyan. A study on online-marketing performance evaluation of real estate firm in the mobile internet Era. China Real Estate.Vol.30(2017).No.4,P.21-32. 